\title{
Long-Term Functional Results of Patients Operated for Isolated Discrete Subaortic Stenosis
}

\author{
Veysel Sahin, MD,${ }^{1}$ Savas Demirpence, $M D,{ }^{2}$ Funda Tetik, $M D,{ }^{1}$ Faik Fevzi Okur, $M D,{ }^{3}$ Emin Alp Alayunt, $M D^{3}$ \\ ${ }^{1}$ Department of Cardiovascular Surgery, Sttkı Kocman Unıversity Training and Research Hospital, Mugla; \\ ${ }^{2}$ Department of Pediatric Cardiology, Cigli Training and Research Hospital, Izmir; \\ ${ }^{3}$ Department of Cardiovascular Surgery, Private Gazi Hospital, Izmir
}

\section{ABSTRACT}

Background: This study aimed to examine the long-term functional results of patients with isolated discrete subaortic stenosis who underwent subaortic membrane resection and myectomy, using transthoracic M-mode echocardiography and 2D speckle-tracking echocardiography.

Methods: Twenty patients operated for isolated discrete subaortic stenosis and 31 controls were included in the study. Patients underwent subaortic membrane resection and myectomy. During the long-term follow up, patients were evaluated with transthoracic M-mode echocardiography and 2D speckle-tracking echocardiography for functional assessment.

Results: The mean age at operation and mean duration of follow up was $8.1 \pm 5.6$ years and $7.2 \pm 3.3$ years, respectively. Interventricular septal thickness at diastole $(0.9 \pm 0.1$ vs. $0.8 \pm 0.1 \mathrm{~cm}, P=0.001)$, ejection time $(285.7 \pm 26.2$ vs. $261.2 \pm 24.3 \mathrm{msec}, P=0.001)$, and aortic strain $(15.6 \pm 3.7 \mathrm{vs}$. $10.5 \pm 4.0, P<0.001)$ were significantly higher in patients. On the other hand, ejection fraction $(64.9 \pm 6.1$ vs. $75.1 \pm 5.4 \%$, $P<0.001)$, fractional shortening $(35.0 \pm 5.1$ vs. $43.7 \pm 5.1, P<$ 0.001 ), and corrected velocity circumferential fiber shortening $(0.12 \pm 0.02$ vs. $0.17 \pm 0.03, P<0.001)$ were significantly lower, when compared with the controls. Longitudinal strain value significantly differed among the groups, with patients having significantly lower strain $(18.8 \pm 1.8$ vs. $20.1 \pm 2.1, P=$ 0.021 ).

Conclusion: In patients operated for isolated discrete subaortic stenosis, aortic gradient seems to continue in the long-term, with persistence of low longitudinal strain.

\section{INTRODUCTION}

Subvalvular aortic stenosis (SAS) has two subtypes, namely the discrete (membranous) and diffuse (muscular hypertrophic), with some patients having the mixed form. In

Received March 19, 2021; received in revised form April 3, 2021; accepted April 14, 2021.

Correspondence: Veysel Sabin, MD, Kotekli Mah. 220. Sok No: 84 Mentese/ Mugla, Telephone+905055664122 (e-mail:veyselkv@@gmail.com). discrete subaortic stenosis (DSS), obstruction may be focal or may lead to a tunnel-like left ventricular outlet narrowing. Although SAS generally takes the form of DSS, tunnel-type lesions present with significant narrowing [Aboulhosn 2006]. The progression rate of DSS is unpredictable and in certain patients with quick progression, the clinical picture may be complicated by aortic valve failure [Van der Linde 2013].

This condition is seldom seen in newborns and infants. SAS is thought to represent an acquired rather than a congenital condition. DSS presents itself as a fibromuscular ring below the aortic valve and may be isolated or occur in conjunction with certain other congenital anomalies, such as ventricular septal defect, patent ductus arteriosis, aortic coarctation, bicuspid aortic valve, abnormal left ventricular papillary muscle, atrioventricular septal defect, and persistent superior vena cava [Ruzmetov 2006; Tal 2021].

The spectrum of surgical therapeutic strategies varies from early surgery in patients with mild to moderate narrowing to late surgery in markedly symptomatic patients. Although early surgery is recommended for the prevention of aortic valve injury, its effectiveness in preventing the postsurgery recurrences is controversial [Van der Linde 2013].

In this study, long-term results of surgery in patients with isolated DSS were compared with a group of controls, with a particular emphasis on the results of transthoracic M-mode echocardiography and 2D speckle-tracking echocardiography assessments.

\section{MATERIALS AND METHODS}

Patients: Seventy-nine patients underwent surgery, due to SAS in our unit between January 2001 and December 2012. Patients with additional pathological conditions were excluded and only those with isolated DSS $(N=20)$ were included. Thirty-one subjects with innocent murmurs who had no known cardiac pathology served as controls for comparisons. The study protocol was approved by the local ethics committee, and the study was conducted in accordance with the principles of the Declaration of Helsinki. All patients or legal representatives provided informed consent prior to study entry.

Surgical procedures - surgical indications were as follows: a pressure gradient of $30 \mathrm{~mm} \mathrm{Hg}$ between the left ventricle and aorta, and identification of the subaortic membrane 
in echocardiography. All procedures were performed by the same pediatric cardiac surgeon under standard cardiopulmonary bypass with moderate systemic hypothermia. Myocardial protection was provided by using antegrade, retrograde, and combined antegrade/retrograde cold cardioplegia. After commencement of cardiopulmonary bypass and cardiac arrest, oblique aortotomy in the direction of non-coronary sinus was performed. Subaortic membrane was exposed through careful retraction of aortic valves, and the subaortic membrane with adjacent hypertrophic muscle tissue were excised circumferentially. The myectomy resection is started by making two parallel incisions in the septum; the first incision is made below the base of the right coronary cusp and the second is made between the right and left coronary cusps below the commissure. These incisions are conjoined superiorly with a third incision below the aortic annulus, and a wedge of septal tissue is resected. After ascertaining the complete removal of the left ventricular outlet obstruction by means of membrane resection and myectomy, left ventricle was rinsed with cold physiological saline solution, and the aortotomy was closed.

Echocardiography: Follow-up assessments were performed by echocardiography and electrocardiography. Transthoracic echocardiography was performed using a Philips HD15 Purewave device. B-mode gray mode images were obtained at the level of apical four chambers and papillary muscle using the parasternal short-axis images. M-mode twodimensional images were obtained from parasternal long axis images. Interventricular septal wall thickness, left ventricular posterior wall thickness, and left ventricular internal diameter were measured in all children. AR was graded on a clinical scale, ranging from "none" to "severe." Grading was multiparametric and integrative. The following data were obtained to arrange the severity of AR: Left ventricular size was classified as normal or dilated, according to the ASE (American Society of Echocardiography) guidelines on native valvular regurgitation; the regurgitant jet was evaluated for flow convergence, vena contracta, and jet area in parasternal long-axis and apical views. ASE guidelines were followed in the assessment of left ventricular systolic and diastolic functions [Lang 2005]. For each measurement, three cardiac cycles were averaged. Systolic functions of the left ventricle (LV) were evaluated, using shortening fraction and ejection fraction. Left ventricular mass was calculated, using the Devereux formula [Devereux 1977].

Two-dimensional speckle-tracking echocardiography (STE) is a technique based on frame-by-frame tracking of tiny echo-dense speckles within the myocardium and subsequent measurement of LV deformation [Leitman 2004; Caivano 2020]. 2D strain values were measured by using a dedicated, customized software package (Philips Purewave, Q lab) in accordance with the guidelines of the American Society of Echocardiography [Lang 2005]. The software calculated longitudinal, circumferential, and radial strains for the respective segments in each view. Figure 1 illustrates the calculation of longitudinal strain from apical 2-chamber view. (Figure 1)

Statistical analysis: Statistical Package for Social Sciences (SPSS) was used for the analysis of data. Normality of the data was tested using Shapiro-Wilk test. Categorical data are presented as frequency (percentage) and continuous data are presented as mean \pm standard deviation. For the comparison of categorical data, Pearson chi-square test was used. Intergroup comparisons of continuous variables were done using student t-test for independent samples or Mann Whitney $\mathrm{U}$ test, depending on the normality of data distribution. Within-group comparison of the continuous variable aortic gradient was done using Wilcoxon sign rank test. A two-sided $P$ value $<0.05$ was considered as an indication of statistical significance.

\section{RESULTS}

Table 1 shows the demographical and clinical parameters of patients and controls. (Table 1) In the patient group, the mean age at operation and mean duration of follow up was $8.1 \pm 5.6$ years and $7.2 \pm 3.3$ years, respectively. At follow up, the mean pressure gradient at the left ventricular outflow tract decreased from $73.4 \pm 23.7 \mathrm{mmHg}$ to $22.8 \pm 19.3(P<0.001)$. Two patients required reoperation and none of the patients died during the study period. During follow up, seven patients developed block (first degree AV block in three patients, left bundle branch block in two patients, and right bundle branch block in two patients). In addition, nine patients developed varying degrees of aortic valve insufficiency in the long-term.

Tables 2 through 4 show the comparisons of follow-up parameters of patients with controls. Patients had significantly longer PR interval $(148.0 \pm 22.0$ vs. $128.7 \pm 9.0 \mathrm{msec}, P=$ $0.001)$, QRS duration $(95.2 \pm 18.2$ vs. $77.9 \pm 5.7 \mathrm{msec}, P<0.001)$, OTc interval $(416.0 \pm 25.9$ vs. $398.3 \pm 22.4$, msec, $P=0.040)$, and $P \min (48.5 \pm 5.6$ vs. $43.6 \pm 8.8 \mathrm{msec}, P=0.003)$ values when compared with controls. (Table 2) (Table 3) (Table 4)

Among M-mode echocardiography measurements, interventricular septal thickness at diastole $(0.9 \pm 0.1$ vs. $0.8 \pm 0.1$ $\mathrm{cm}, P=0.001)$, ejection time $285.7 \pm 26.2$ vs. $261.2 \pm 24.3$ msec, $P=0.001)$, and aortic strain $(15.6 \pm 3.7$ vs. $10.5 \pm 4.0, P$ $<0.001)$ were significantly higher in patients. On the other hand, ejection fraction $(64.9 \pm 6.1$ vs. $75.1 \pm 5.4 \%, P<0.001)$, fractional shortening ( $35.0 \pm 5.1$ vs. $43.7 \pm 5.1, P<0.001)$, and corrected velocity circumferential fiber shortening $(0.12 \pm 0.02$ vs. $0.17 \pm 0.03, P<0.001)$ were significantly lower, when compared with controls. Among two-dimensional speckle-tracking echocardiography measurements, only longitudinal strain value significantly differed among groups with patients having significantly lower strain $(18.8 \pm 1.8$ vs. $20.1 \pm 2.1, P=0.021)$.

\section{DISCUSSION}

The signs of DSS are a result of the geometric and anatomic alterations in the left ventricular outlet. Its pathophysiology is thought to involve an acquired process rather than a congenital one. This endocardial anomaly is not limited to the subaortic ridge, but also involves the adjacent valvular structures [Darcin 2003]. The indications for surgical treatment include the presence of a pressure gradient in the LVOT, aortic valve failure, aortic coarctation, PDA, VSD, 
Table 1. Comparison of patients versus controls in terms of demographical and clinical parameters

\begin{tabular}{lccc}
\hline & Patients $(N=20)$ & Controls $(N=31)$ & $P$ \\
\hline Age $(y)$ & $15.2 \pm 6.9$ & $11.2 \pm 3.5$ & 0.022 \\
Sex $(\mathrm{M} / \mathrm{F})$ & $12 / 8$ & $16 / 15$ & 0.557 \\
$\mathrm{BMl}\left(\mathrm{kg} / \mathrm{m}^{2}\right)$ & $18.9 \pm 5.9$ & $19.2 \pm 3.4$ & 0.380 \\
BSA $\left(\mathrm{m}^{2.7}\right)$ & $3.1 \pm 1.1$ & $2.9 \pm 0.9$ & 0.500 \\
SBP $(\mathrm{mmHg})$ & $118.0 \pm 28.0$ & $106.0 \pm 9.7$ & 0.161 \\
DBP $(\mathrm{mmHg})$ & $69.5 \pm 11.0$ & $70.0 \pm 7.2$ & 0.953 \\
PP $(\mathrm{mmHg})$ & $48.5 \pm 20.6$ & $36.9 \pm 7.6$ & 0.004 \\
\hline
\end{tabular}

BSA, body surface area; BMI, body mass index; PP, pulse pressure; SBP, systolic blood pressure; DBP, diastolic blood pressure
Table 2. Comparison of patients versus controls in terms of electrocardiography measurements

\begin{tabular}{lccc}
\hline & Patients $(N=20)$ & Controls $(N=31)$ & $P$ \\
\hline Heart rate, beat/min & $78.0 \pm 18.1$ & $79.1 \pm 13.0$ & 0.369 \\
PR interval, msec & $148.0 \pm 22.0$ & $128.7 \pm 9.0$ & 0.001 \\
QRS duration, msec & $95.2 \pm 18.2$ & $77.9 \pm 5.7$ & $<0.001$ \\
QRS axis, degrees & $47.3 \pm 45.0$ & $49.5 \pm 17.2$ & 0.831 \\
QTc interval, msec & $416.0 \pm 25.9$ & $398.3 \pm 22.4$ & 0.040 \\
Pmax, msec & $89.0 \pm 8.0$ & $85.7 \pm 10.7$ & 0.149 \\
Pmin, msec & $48.5 \pm 5.6$ & $43.6 \pm 8.8$ & 0.003 \\
PWD, msec & $40.0 \pm 8.6$ & $42.1 \pm 8.5$ & 0.356 \\
\hline
\end{tabular}

PWD, $\mathrm{p}$ wave dispersion

Table 3. Comparison of patients versus controls in terms of M-mode echocardiography measurements

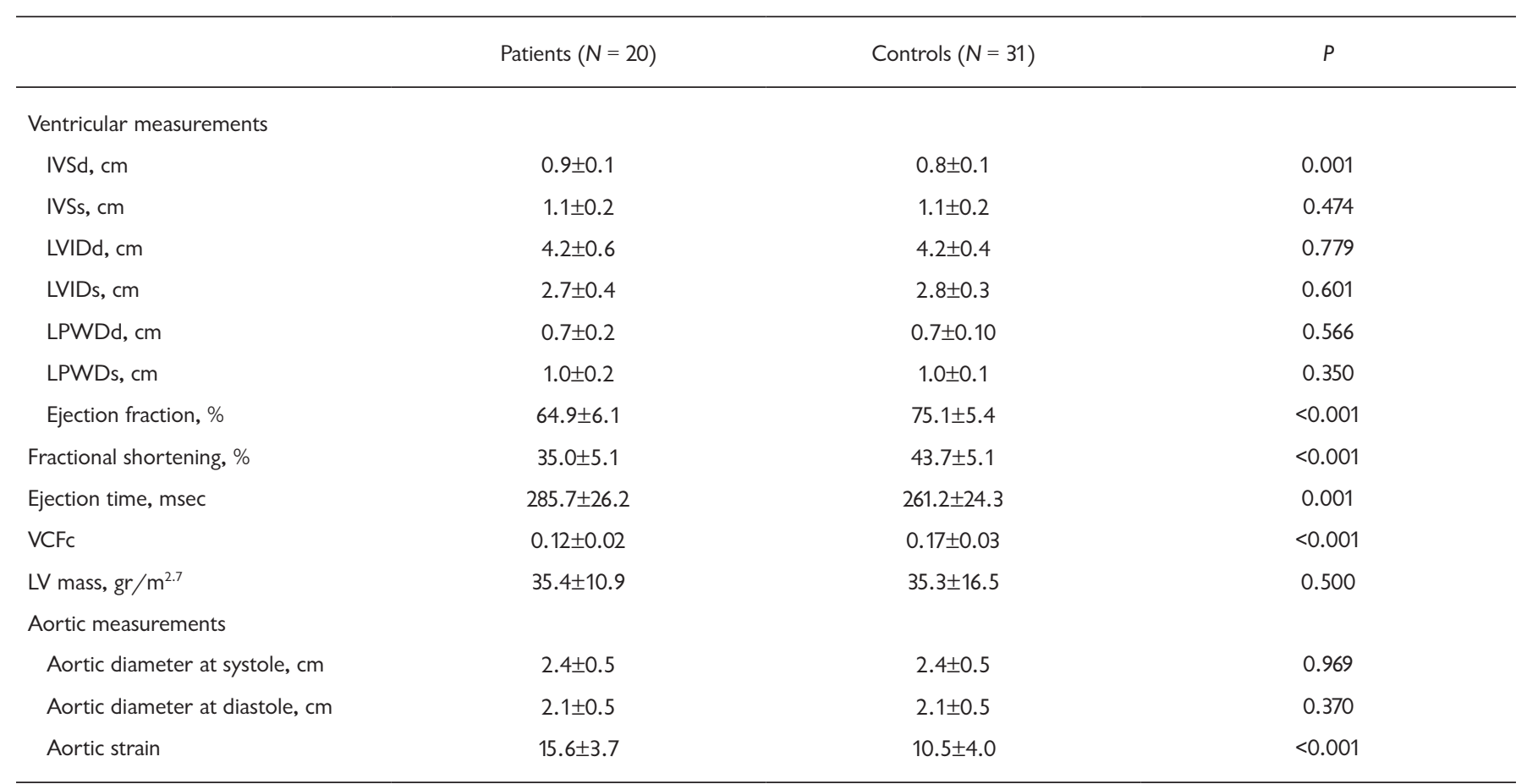

IVSd, cm; interventricular septal thickness at diastole; IVSs, cm; interventricular septal thickness at systole; LVIDd: left ventricle internal diameter at diastole; LPWDd, left ventricular posterior wall dimension, diastole; LPWDs, left ventricular posterior wall dimension, systole; VCFc, corrected velocity circumferential fiber shortening (fractional shortening/ejection time)

Table 4. Comparison of patients versus controls in terms of two-dimensional speckle-tracking echocardiography-based measurements

$\begin{array}{lccc} & \text { Patients }(N=20) & \text { Controls }(N=31) & P \\ \text { Longitudinal strain, \% } & 18.8 \pm 1.8 & 20.1 \pm 2.1 & 0.021 \\ \text { Radial strain, \% } & 42.2 \pm 7.9 & 44.0 \pm 14.0 & 0.569 \\ \text { Circumferential strain, \% } & 17.3 \pm 2.8 & 18.2 \pm 4.3 & 0.417\end{array}$


AVSD, or other concomitant cardiac anomalies. Definitive treatment for DSS involve surgical correction of the obstruction, which may consist of simple membrane removal or extensive ring resection with or without surgical myectomy. The controversy surrounding the timing and method of surgical treatment stems from the fact that DSS may progress even after surgery [Darcin 2003; Dorobantu 2014; Abushaban 2019], with reported restenosis rates between 6 and 30\% [Abushaban 2019]. Rayburn et al. [Rayburn 1997] followed 23 patients for 14 years using a surgical technique that was similar to ours and found a greater progression rate of the LVOT gradient in the non-myectomy group as compared with cases who underwent myectomy, leading to their suggestion to perform myectomy in addition to subaortic membrane resection.

A careful assessment of the reported cases of progression points out to the common coexistence of other pathological conditions, such as aortic coarctation accompanying DSS. In our series, patients with aortic coarctation were excluded and a significant decrease in the preoperative LVOT gradient was observed, with no significant signs of progression. Also, patients with other cardiac pathologies, such as VSD that may trigger wall stress and proliferation through creation of blood flow turbulence, were excluded and early diagnosis and early surgery while the gradient is still below $30 \mathrm{~mm} \mathrm{Hg}$ have been shown to improve clinical outcomes and decrease the risk of aortic failure [Brauner 1997].

Other than congenital anomalies accompanying DSS, acquired aortic valve failure appears to be the most common condition coexisting with DSS. When DSS is not treated, aortic failure enters into a state of quick progression. Aortic valve failure is thought to result from the presence of thick fibrous tissue found in the ventricular surface of the aortic valves. The fibrosis in the leaflets of the aortic valve develops due to the repeating trauma caused by the blood flow jet at the stenotic area or due to the discrete membrane itself. This fibrous tissue section under the aortic valve plays an important role in the retraction of the aortic valves [Darcin 2003]. Despite studies suggesting that quick progression of aortic valve failure may continue even in patients undergoing early surgical treatment of DSS [Oliver 2001; Opotowsky 2017], others have found preservation of aortic valve integrity and marked reduction in the progression of aortic failure with early membrane resection and adequate myectomy, as supported by our findings [Rayburn 1997; Dorobantu 2014; Abushaban 2019]. In the study by Van der Linde et al. [Van der Linde 2013], mild aortic valve insufficiency was found to persist in $20 \%$ of the patients during the long-term follow up without further progression. In our study, $30 \%$ of the patients had mild aortic valve insufficiency without progression, with only two patients $(10 \%)$ having moderately severe aortic valve insufficiency, consistent with other studies in which early surgery was implemented.

Although the surgical correction of DSS generally has excellent short-term outcomes with low mortality, it is associated with up to an $8 \%$ chance of an iatrogenic VSD and up to $14 \%$ chance of complete atrioventricular block [Rohlicek 1999]. There were no iatrogenic VSD or complete atrioventricular block in our study. DSS represents an acquired condition rather than a congenital one that results from the variations in the cardiac anatomy, although the exact triggering mechanisms are yet to be defined. In this regard, several theories have been put forward to explain the underlying mechanisms. Despite the absence of marked echocardiographic findings in the early childhood, a sharper ventricularaortic angle has been defined in DSS patients [Foker 2013], leading to increased wall stress on the ventricular surfaces of the aortic valves and LVOT. Increased wall stress stimulates the endothelial proliferation in LVOT, which is thought to trigger the pathological process [Oxborough 2009; Qureshi 2015].

Echocardiography allows the detection of narrowing in the left ventricular outlet, turbulent flow, ventricular hypertrophy, pressure gradient and the flatter occurring in the aortic valves during the systole in patients with DSS. The most important questions that remain unanswered are whether the reduction in LVOT pressure gradient by membrane resection and myectomy results in a change in the geometry of the ventricles in the long term, whether turbulent flow and aortic valve flatter continues, and whether aortic valve injury resulting from these factors can be prevented. Recently introduced strain (S) and strain rate (SR) echocardiography enables detailed assessment of the regional and global ventricular functions. The likelihood of tethering or translational artifacts is very low in S and SR, with a lower degree of load-dependence in the evaluation of global and regional ventricle functions. While myocardial S measurements show the deformations in a specific tissue area, SR simply reflects the deformation rate. During the ventricular contraction and relaxation, the deformation can be observed in all three planes (radial, circumferential and longitudinal). In addition, the two-dimensional (2D) speckle tracking represents a novel ultrasound modality used for myocardial S and SR estimations.

In the present study, our objective was to assess the success of DSS surgery, in terms of the preservation of functional and structural improvements after surgery in the intermediate- and long-term using transthoracic echocardiography and 2D speckle tracking. Our results suggest the aortic gradient continues in the long term, with persistence of low longitudinal strain, indicating partial persistence of the condition. We believe that these findings should be corroborated with relevant studies at the cellular level.

\section{REFERENCES}

Aboulhosn J, Child JS. 2006. Left ventricular outflow obstruction: subaortic stenosis, bicuspid aortic valve, supravalvar aortic stenosis, and coarctation of the aorta. Circulation 114:2412-22.

Abushaban L, Uthaman B, Selvan JP, Al Qbandi M, Sharma PN, Vel Mariappa T. 2019. Long term follow up and outcomes of discrete subaortic stenosis resection in children. Ann Pediatr Cardiol. 12(3):212-219.

Brauner R, Laks H, Drinkwater DC, Jr., Shvarts O, Eghbali K, Galindo A. 1997. Benefits of early surgical repair in fixed subaortic stenosis. J Am Coll Cardiol 30:1835-42.

Caivano D, Rishniw M, Baiona L, Birettoni F, Nisini N, and Porciello F. 2020. Assessment of Longitudinal Left Ventricle Deformation by 
2-Dimensional Speckle Tracking Echocardiography Obtained from Different Views in Cats. Vet Sci. 6;7(3):104.

Darcin OT, Yagdi T, Atay Y, Engin C, Levent E, Buket S, et al. 2003. Discrete subaortic stenosis: surgical outcomes and follow-up results. Tex Heart Inst J 30:286-92.

Devereux RB, Reichek N. 1977. Echocardiographic determination of left ventricular mass in man. Anatomic validation of the method. Circulation 55:613-8.

Dorobantu DM, Sharabiani MT, Martin RP, Angelini GD, Parry AJ, Caputo M, et al. 2014. Surgery for simple and complex subaortic stenosis in children and young adults: results from a prospective, procedure-based national database. J Thorac Cardiovasc Surg 148:2618-26.

Foker JE. 2013. Outcomes and questions about discrete subaortic stenosis. Circulation 127:1447-50.

Lang RM, Bierig M, Devereux RB, Flachskampf FA, Foster E, Pellikka PA, et al. 2005. Recommendations for chamber quantification: a report from the American Society of Echocardiography's Guidelines and Standards Committee and the Chamber Quantification Writing Group, developed in conjunction with the European Association of Echocardiography, a branch of the European Society of Cardiology. J Am Soc Echocardiogr 18:1440-63.

Leitman M, Lysyansky P, Sidenko S, Shir V, Peleg E, Binenbaum M, et al. 2004. Two-dimensional strain-a novel software for real-time quantitative echocardiographic assessment of myocardial function. J Am Soc Echocardiogr 17:1021-9.

Oliver JM, Gonzalez A, Gallego P, Sanchez-Recalde A, Benito F, Mesa JM. 2001. Discrete subaortic stenosis in adults: increased prevalence and slow rate of progression of the obstruction and aortic regurgitation. J Am Coll Cardiol 38:835-42.
Opotowsky AR, Pickard SS, Geva T. 2017. Imaging adult patients with discrete subvalvar aortic stenosis. Curr Opin Cardiol. 32(5):513-520.

Oxborough D, Batterham AM, Shave R, Artis N, Birch KM, Whyte G, et al. 2009. Interpretation of two-dimensional and tissue Doppler-derived strain (epsilon) and strain rate data: is there a need to normalize for individual variability in left ventricular morphology? Eur J Echocardiogr 10:677-82.

Qureshi A, Awuor S, Martinez M. 2015. Adult presentation of subaortic stenosis: another great hypertrophic cardiomyopathy mimic. Heart Lung Circ 24:e7-e10.

Rayburn ST, Netherland DE, Heath BJ. 1997. Discrete membranous subaortic stenosis: improved results after resection and myectomy. Ann Thorac Surg 64:105-9.

Rohlicek CV, del Pino SF, Hosking M, Miro J, Côté JM, Finley J, et al. 1999. Natural history and surgical outcomes for isolated discrete subaortic stenosis in children. Heart 82:708-13.

Ruzmetov M, Vijay P, Rodefeld MD, Turrentine MW, Brown JW. 2006. Long-term results of surgical repair in patients with congenital subaortic stenosis. Interact Cardiovasc Thorac Surg 5:227-33.

Tal N, Golender J, Rechtman Y, Tidhar D, Erez E. 2021. Long-Term Aortic Valve Function in Patients With or Without Surgical Treatment for Discrete Subaortic Stenosis. Pediatr Cardiol. 42(2):324-330.

Van der Linde D, Roos-Hesselink JW, Rizopoulos D, Heuvelman HJ, Budts W, van Dijk AP, et al. 2013. Surgical outcome of discrete subaortic stenosis in adults: a multicenter study. Circulation 127:1184-91, e1-4.

Van der Linde D, Takkenberg JJ, Rizopoulos D, Heuvelman HJ, Budts W, van Dijk AP, et al. 2013. Natural history of discrete subaortic stenosisin adults: a multicentre study. Eur Heart J 34:1548-56. 